\title{
Prevalence of a marker of active helicobacter pylori infection among patients with type 2 diabetes mellitus in Lagos, Nigeria
}

\author{
Aderemi Oluyemi $^{1 *}$, Ebere Anomneze ${ }^{2}$, Stella Smith ${ }^{3}$ and Olufemi Fasanmade ${ }^{4}$
}

\begin{abstract}
Background: There appears to exist a potentially important interplay between diabetes mellitus (DM) and Helicobacter pylori (H. pylori) infection. Findings from previous studies have been conflicting. Only a few studies have examined the topic in a sub-Saharan African population. This study sought to determine the prevalence of H. pylori infection among Type 2 diabetes mellitus (T2DM) patients in Lagos, Nigeria.

Findings: $\mathrm{H}$. pylori infection was detected in 18\% of T2DM patients and 13\% of controls but there was no statistical significance in this difference $(p=0.52)$. The prevalence of $\mathrm{H}$. pylori was neither associated with the known duration of T2DM nor was it associated with age, gender, body mass index (BMI), smoking status. T2DM was not shown to be a risk factor independently associated with risk for $\mathrm{H}$. pylori infection $(\mathrm{OR}=0.87,95 \% \mathrm{Cl}=0.58-1.31, \mathrm{p}=0.57)$.

Conclusions: The lack of a statistical significant difference between the $H$. pylori infection rates in T2DM patients and controls suggests that the infection is not increased in T2DM. Larger studies need to be conducted to confirm the study findings.
\end{abstract}

Keywords: Helicobacter pylori infection, Stool antigen test, Diabetes mellitus, Nigeria

\section{Background}

Since the discovery of the bacterium by Warren and Marshal in 1984 [1], Helicobacter pylori has been shown to have a world-wide distribution. It has been estimated that up to half of the world's population harbor the infection in their stomachs [2]. The developing world has a higher prevalence rate of infection than the developed world and it has associated with both gastrointestinal and extra-intestinal ailments [3].

An increased prevalence of $H$. pylori infection among diabetes mellitus patients was first suggested by a report from Hungary [4]. It was further supported by other reports [5,6]. The latter study [6], documented a H. pylori prevalence rate of $74.4 \%$ in Type 2 diabetes mellitus patients as against $50 \%$ in non-diabetic controls. Another study in Italy corroborated this finding [7]. However, other more recently published data have concluded otherwise. A large Australian study [8] showed that there

\footnotetext{
* Correspondence: remioluyemi@yahoo.com

'General Hospital, Ikorodu, Lagos State, Nigeria

Full list of author information is available at the end of the article
}

was no significant difference in prevalence of $H$. pylori infection in DM versus(vr) non-DM patients. The higher prevalence of infection among normal children as opposed to those with type 1 DM [9] further strengthens this opposing argument especially as childhood is thought to be the most common period of acquisition of $H$. pylori infection.

An earlier report by Ugwu et al. [10] from Nigeria examined the possibility of such a relationship in our local environment. The study reported no significant difference in the prevalence of $H$. pylori infection between diabetics and non-diabetics ( $35 \%$ vr $28 \%, \mathrm{p}>0.05)$. The study was unique as there exists little data examining this topic in sub-Saharan populations.

The mode of diagnosis that was deployed in this study, the stool antigen testing, identifies active infection unlike the serological based modalities of diagnosis which cannot distinguish between current and previous infections [11]. This study sought to determine the prevalence of H. pylori infection among T2DM patients in Lagos, South-West region of Nigeria.

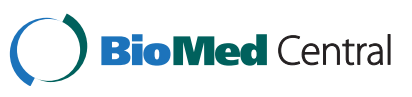




\section{Methods}

The study is a hospital-based, cross-sectional survey and was conducted at the Lagos University Teaching Hospital (LUTH), which is situated in Idi-Araba, Lagos State, Nigeria. It is the largest tertiary health facility in the commercial nerve centre of Nigeria and it's catchment area of patients is state-wide with extension to adjoining states in the South West region. After obtaining informed consent, 100 consecutive, consenting T2DM patients and 100 controls were recruited from the adult out-patient wing of LUTH. Age and gender-matched controls were selected from non-diabetic volunteers among LUTH staff, students and patients' relations. The controls were randomly requested to participate and only consenting ones were recruited for the study. After agreeing to participate and signing informed consent forms, all respondents had standard pretested written questionnaires administered to them by medical doctors. They were then required to submit fresh stool samples which were tested for evidence of active $H$. pylori infection by stool antigen positivity with the immunoassay-based Rapid Strip $\mathrm{HpSA}^{\mathrm{TM}}$ according to the manufacturer's instructions (from Meridian Bioscience Europe)(sensitivity 96.1\%, specificity 90.6\%) [12].

Each of the controls had blood drawn for fasting blood glucose and those that met the minimum World Health Organization requirement for diabetes mellitus diagnosis were excluded from being controls in this study. This minimum criterion is a fasting plasma glucose of $\geq 7.1 \mathrm{mmol} / \mathrm{l}$ [13]. As diarrheic stools are not appropriate for testing with the above mentioned kit [12], this was taken as an exclusion criterion for both cases and controls. Also excluded were those who had had prior antibiotic and proton pump therapy for $H$. pylori infection.

Ethical approval was obtained from the Research and Ethics Committee of LUTH prior to the commencement of the study.Data obtained was analyzed using the statistical software Epi-info version 6. Results are expressed as means \pm standard deviation and frequencies. Statistical analysis was done using the students' t-test for continuous variables and the chi-squared(x2) for categorical data. Multivariate analyses were conducted in view of possible confounding factors.

\section{Findings}

Both study cases and controls had similar sociodemographic and anthropometric profiles and Table 1 summarizes the parameters examined.

\section{Prevalence of Helicobacter pylori infection in cases and Non-diabetic controls}

H. pylori infection as determined by stool antigen positivity was present in $18 \%(n=100)$ of type 2 diabetic patients and $13 \%(n=100)$ of the controls(Table 2$)$. There was no significant difference in overall prevalence of
Table 1 Socio-Demographic and arthropometric data of participants with type $\mathbf{2}$ diabetes mellitus and controls in LUTH, Lagos

\begin{tabular}{llll}
\hline Characteristics & $\begin{array}{l}\text { Cases } \\
\text { (n= 100) }\end{array}$ & Control(n= 100) & p value \\
\hline Age (years) & Mean & Mean & 0.15 \\
Sex: Male (\%) & $46.4 \pm 10.40$ & $54.9 \pm 10.30$ & \\
Female (\%) & 45 & 0.89 \\
Duration of Diabetes & Mean & Not & \\
Mellitus (year) & $17.41 \pm 8.33$ & applicable & applicable \\
Smoking Status: No (\%) & 82 & 80 & 0.45 \\
Yes (\%) & 18 & 20 & \\
Level of Education:- & 11 & 9 & 0.82 \\
None (\%) & & & \\
Primary (\%) & 13 & 22 & \\
Secondary (\%) Post- & 23 & 27 & \\
Secondary (\%) & 53 & 42 & \\
\hline
\end{tabular}

H. pylori in cases and controls $\left(\mathrm{x}^{2}=0.41, \mathrm{p}=0.52\right)$. Of the 13 infected control subjects, the prevalence was higher in men $(7 / 45)$ than in women(6/55) $(15.6 \% \mathrm{vr}$ $\left.10.9 \%, \mathrm{x}^{2}=0.09, \mathrm{p}=0.75\right) . H . \quad$ pylori-positive control subjects were not significantly younger than $H$. pylorinegative subjects $(53.6 \pm 12.30$ vr $55.1 \pm 10.04$ years, $\mathrm{p}=0.84$ ); The overall prevalence of $H$. pylori infection was $18 \%(\mathrm{n}=100)$ in patients with T2DM. The prevalence of $H$. pylori infection was $16.4 \%(7 / 43)$ in men and $21.1 \%$ $(12 / 57)$ in women with T2DM $\left(\mathrm{x}^{2}=0.06, \mathrm{p}=0.81\right)$. The $H$. pylori-positive type $2 \mathrm{DM}$ patients were noted to be were slightly older than $H$. pylori-negative counterparts in this study but the difference was also not statistically significant $(55.1 \pm 9.95$ vr $56.7 \pm 10.53$ years, $\mathrm{p}=0.91)$.

The prevalence of $H$. pylori infection was not associated with the known duration of T2DM. The prevalence of the infection was $26.9 \%(7 / 26)$ in patients with T2DM diagnosed $\leq 2$ years prior, $20.8 \%(5 / 24)$ in those diagnosed $2-5$ years prior, and $14 \%(7 / 50)$ in those diagnosed $\geq 5$ year duration $\left(\mathrm{x}^{2}=1.25, \mathrm{p}=0.52\right)$. There were 24 obese T2DM in this study as against 17 in the control group. $H$. pylori was positive in $12.5 \%$ of obese diabetics $(3 / 24)$ and $19.7 \%(15 / 76)$ of diabetics with normal BMI $\left(\mathrm{x}^{2}=0.14, \mathrm{p}=0.74\right)$. There was no association between H. pylori infection and smoking history; the prevalence of the infection was $32.5 \%(66 / 203)$ in those with a

Table 2 Comparison of $\boldsymbol{H}$. pylori status among study participants with type 2 diabetes mellitus and controls in LUTH, Lagos

\begin{tabular}{llll}
\hline & Cases $(n=100)$ & Controls $(\mathbf{n}=100)$ & Total $(=\mathbf{2 0 0})$ \\
\hline H. pylori POSITIVE & 18 & 13 & 31 \\
H. pylori NEGATIVE & 82 & 87 & 169 \\
\hline
\end{tabular}


previous or current smoking history and 31.1\% (68/219) in non-smokers $\left(\mathrm{x}^{2}=0.02, \mathrm{p}=0.89\right)$.

In patients with diabetes and control subjects, logistic regression analysis (including age, gender, diabetes status, BMI, level of education and smoking history) revealed that not any one of the above mentioned factors was independently associated with $H$. pylori infection.

\section{Discussion}

\section{Prevalence of $H$. pylori infection in type 2 diabetes} mellitus patients and controls

There was no significant difference in the prevalence of H. pylori in cases and controls $(\mathrm{x} 2=0.41, \mathrm{p}=0.52)$. The results therefore show that $H$. pylori infection is not significantly associated with type 2 diabetes mellitus in this study population.

Ugwu et al. [10] had reported similar findings from the South East region of Nigeria as there was no significant association between the infection prevalence in their diabetic population and non-diabetic controls(35\% vr $28 \%$ respectively, $\mathrm{p}=0.432$ ). The findings are also in keeping with the results from various other regions of the world both developed-Australia [8], Italy [9] and developing-China [14], Turkey [15], Romania [16].

However, there exists in scientific literature, other conflicting data as reported by several investigators. In 1989, Simon et al. [4] reported that infection rates were significantly higher in diabetics than in their controls. This was the first report to examine for a possible relationship between $H$. pylori and DM. It used rapid urease test to detect infection but a major confounder, age, was not adjusted for in comparison between the groups of patients and controls.

Current thinking about the natural history of $H$. pylori infection is that childhood remains the most important period of acquisition and that spontaneous clearance of infection occurs with increasing frequency as time progresses $[17,18]$. Hence, the role of age in this issue is quite prominent and it should have been adjusted for before coming to conclusions about any hypothesized association. Another report that supported the positive association was from Oldenburg et al. [19]. A review of this seropositivitybased paper reveals that there was a significant difference between the ages of the diabetics and that of the controls as has also been noted by Xia et al. [8]. Thus, drawing conclusions without adjusting for this important variable may have led to the conclusion of Oldenburg et al. [19] (especially as their own analysis had showed a significantly higher prevalence was observed only in the 60-70 year olds).

The influence of age cannot be overemphasized as for instance, the initial significantly less prevalence of $H$. pylori between the type 1 diabetics and their type 2 counterparts and even those of controls disappeared when appropriate adjustments for age were made in a large Australian study [8].

Poor socioeconomic status, living conditions, and hygiene have been repeatedly demonstrated to be major risk factors for $H$. pylori infection [9,14]. Dore et al. [9] has also observed that the studies that found an association between DM and $H$. pylori infection often did not correct for this very important confounding variable. Moreover, it must be noted that the research tool employed for the detection of $H$. pylori seropositivity in the Oldenburg et al study was only $79 \%$ specific and this cannot be considered acceptable by current standards [11].

\section{Local $H$. pylori infection prevalence data as compared with study findings}

$H$. pylori prevalence data from local studies vary widely depending on the population studied and mode of bacterial identification.

Seroprevalence studies predominate and their values vary based on the population studied and mode of $H$. pylori diagnosis. The highest and lowest prevalence values were studies in which the diagnosis of $H$. pylori was made via histology in patients undergoing endoscopy. Eighty-seven percent (78\%) was the highest quoted figure and this was from a hospital-based study among Maiduguri dyspeptics [20] and the lowest figure of $22.4 \%$ was an Ibadan report from among patients with chronic gastritis [21].

The prevalence figures from this index population (18\% in T2DM patients and $13 \%$ in controls) was rather low as compared to the other prevalence data as indicated above. The reasons may not farfetched.

First, it is not appropriate to compare the prevalence data from community-based and hospital-based studies as there remains the inbuilt tendency for bias in doing so. Various factors which come to play in hospital-based studies cannot be easily corrected for during data analysis. Also the hospital-base from which the study participants are drawn lends itself to the explanation that there is a higher likelihood of these patients being exposed to repeated antibiotics that might have anti-helicobacter effects [22]. The mode of diagnosis is also an issue as serology-based studies cannot compensate for the inability of the tests to distinguish between current and previous infection [23]. The stool antigen detection basis of this study represents an attempt at more accurate detection of prevalence of current H. pylori infection in our local population. This was also corroborated by Smith et al [24] in their study of the use of stool antigen test to diagnose $H$. pylori infection.

\section{$H$. pylori infection and duration of diabetes}

This study does not agree with the suggestion that the prevalence of $H$. pylori infection increases with the duration of diabetes. There was no relationship between duration of DM and H. pylori infection. This was in agreement 
with findings from both local [10] and international literature $[8,9,15]$. There still exists controversy in this area as some researchers have noted a significant relationship between $H$. pylori infection and DM duration $[5,25]$ while others have noted a negative relationship [22].

The Italian study [25] showed that the prevalence of $H$. pylori infection was $23 \%, 32 \%$, and $40 \%$ in patients with type 1 diabetes who had a disease duration of $>1$ year, $1-$ 3 year, or $>3$ year, respectively [26]. The age factor, again, appears to have confounded the results of these studies.

The mean ages in the above mentioned groups were 22, 30 , and 37 years, respectively, and it is likely that any association between $H$. pylori infection and duration of DM would disappear if age was adjusted for in the final analyses.

The negative association report [22] was seroprevalencebased and conducted among type 1 diabetics from Spain. The seroprevalence of $H$. pylori infection was $43 \%$ in patients with the duration of $<3 \mathrm{yr}$ and the rate decreased to $16 \%$ for those with a longer duration. The reason adduced for this was that infection decreases during the course of DM disease because of repeated antibiotic therapy.

This study does not support the hypothesis that patients with DM are more frequently infected by $H$. pylori over time.

\section{Conclusions}

The lack of a statistical significant difference between the H. pylori infection rates in T2DM patients and controls suggests that the infection is not increased in T2DM. More empowered and larger studies need to be conducted to confirm the study findings and further elucidate the relationship of these two factors- T2DM and H. pylori infection.

\section{Competing interests}

The authors declare no conflict of interests in the publication of this document.

\section{Authors' contributions}

EA was the initiator of the research topic. He also provided for the materials for the study. AO acted as the principal investigator in this project. SS and OF gave expert input all through the research and contributed to the final editing of this publication particularly from Microbiology and Endocrinology stand points. All authors read and approved the final manuscript.

\section{Author details}

${ }^{1}$ General Hospital, Ikorodu, Lagos State, Nigeria. ${ }^{2}$ Health Gates Consultancy and Medical Services, Ojuelegba, Lagos State, Nigeria. ${ }^{3}$ Division of Molecular Biology, Nigerian Institute of Medical Research, Lagos State, Nigeria. ${ }^{4}$ Department of Medicine, Lagos University Teaching Hospital, Idi-Araba, Lagos State, Nigeria.

Received: 18 November 2011 Accepted: 1 June 2012 Published: 11 June 2012

\section{References}

1. Warren JR, Marshall BJ: Unidentified curved bacilli on gastric epithelium in active chronic gastritis. Lancet 1983, 1:1273-1275.

2. Perez-Perez Gl, Rothenbacher D, Brenner H: Epidemiology of Helicobacter pylori infection. Helicobacter 2004, 9(suppl 1):1-6.

3. Tsang KW, Lam SK: Extragastroduodenal conditions associated with Helicobacter pylori infection. Hong Kong Med J 1999, 5:169-174.
4. Simon L, Tornoczky J, Toth M, Jambor M, Sudar Z: The significance of Campylobacter pylori infection in gastroenterologic and diabetic practice. Orvosi Hetilap 1989, 130:1325-1329.

5. Oldenburger B, Diepersloot RJ, Hoekstra JB: High seroprevalence of Helicobacter pylori in diabetes mellitus patients. Dig Dis Sci 1996, 41:458.

6. Gentile S, Turco S, Oliviero B, Torella R: The role of autonomic neuropathy as a risk factor of Helicobacter pylori infection in dyspeptic patients with type 2 diabetes mellitus. Diab Res Clin Pract 1998, 42:41-48.

7. Marrollo M, Latella G, Melide D, Storelli E, lannarelli R, Stornelli P, et al: Increased prevalence of Helicobacter pylori in patients with diabetes mellitus. Dig Liver Dis 2001, 33(1):21-29.

8. Xia H-HX, Talley JN, Kam EPY, Young LJ, Hammer J, Horowitz M: Helicobacter pylori infection is not associated with diabetes mellitus nor with upper gastrointestinal symptoms in diabetes mellitus. Am J Gastroenterol 2001, 96:1039-1046.

9. Dore MP, Bilotta M, Malaty HM, Pacifico A, Maioli M, Graham DY, et al: Diabetes Mellitus and Helicobacter pylori infection. Nutrition 2000, 16(6):407-410.

10. Ugwu NC, Ugwuja El, Ejkkeme BN, Obeka NC: Helicobacter pylori seropositivity in Nigerians with Type 2 diabetes mellitus. The Internet Journal of Trop Med 2008, 4(2).

11. Malfertheiner P, Megraud F, O'Morain C, Hungin AP, Jones R, Axon A: European Helicobacter pylori Study Group(EHPSG). Current concepts in the management of Helicobacter pylori infection- the Maastricht 2-2000 Consensus report. Alimen. Pharmacol Ther 2002, 16:167-180.

12. Rapid strip $\mathrm{HpSA}^{\mathrm{TM}}$ from Meridian Bioscience Europe Information Pamplet.

13. Definition and Diagnosis of Diabete Mellitus and Intermediate Hyperglycemia. Report of a WHO/IDF Consultation; 2006.

14. Woodward M, Morrison C, McColl K: An investigation into factors associated with Helicobacter pylori infection. J Clin Epidemiol 2000, 53:175-181.

15. Demir M, Migneco A, Nista EC, Gasbarrini G, Gasbarrini A, Pitocco D, et al: Helicobacter pylori prevalence in Diabetes Mellitus patients with Dyspeptic Symptoms and Its Relationship to Glycemic Control and Late Complications. Dig Dis Sci 2008, 53:2646-2649.

16. Stanciu OG, Trifan A, Sfarti C, Cojocariu C, Stanciu C: Helicobacter pylori infection in patients with diabetes mellitus. Rev Med Chir Soc Nat lasi 2003, 107(1):59-65.

17. Holcombe C, Lucas S, Umar H, Abba A: Helicobacter pylori in Africa. Trans R Soc Trop Med Hygiene 1990, 84:294-296.

18. Xia H-X, Talley NJ: Natural acquisition and spontaneous elimination of Helicobacter pylori infection. Am J Gastroenterol 1997, 92:178-187.

19. Oldenburg B, Diepersloot RJ, Hoekstra JB: High seroprevalence of Helicobacter pylori diabetes mellitus patients. Dig Dis Sci 1996, 41:458.

20. Mustapha S, Pindiga U, Yusuph H, Goni B, Jibrin Y: Helicobacter Pylori infection among dyspeptic patients at a Tertiary Hospital in Northern Nigeria. The Internet Journal of Infectious Diseases 2011, 9(2).

21. Oluwasola AO, Ogunbiyi JO: Chronic gastritis and Helicobacter pylori infectionin University College Hospital, Ibadan, Nigeria- a study of 85 fibre optic gastric biopsies. Niger J Med 2004, 13(4):372-378.

22. de Luis DA, de la Calle H, Roy G, Martin de Argila C, Valdezates S, et al: Helicobacter pylori infection and insulin-dependent diabetes mellitus. Diab Res Clin Pract 1998, 39:143-146.

23. Smith SI, Oyedeji KS, Arigbabu AO, Chibututu CC, Anomneze EE, et al: Seroprevalence of Helicobacter pylori infection in patients with gastritis and peptic ulcer in western Nigeria. Br J Biomed Sci 2001, 58(2):97-100.

24. Smith SI, Oyedeji KS, Goodluck HA, Fowora MA, Anomneze E, Lesi F: The use of Helicobacter pylori stool antigen test for the diagnosis of Helicobacter pylori in Lagos, Nigeria. West Indian Medical Journal 2011, 60(1):33-36.

25. Gasbarrini A, Ojetti V, Pitocco D, Armuzzi A, Gentiloni Silveri N, Pola P, et al: Helicobacter pylori infection in patients with insulin-dependent diabetes mellitus. Eur $J$ Gastroenterol Hepatol 1998, 10:469-472.

26. Farup CE, Leidy NK, Murray M, Williams GR, Helbers L, Quigley EM: Effect of domperidone on health-related quality of life of patients with symptoms of diabetic gastroparesis. Diabetic Care 1998, 21:1699-1706.

\section{doi:10.1186/1756-0500-5-284}

Cite this article as: Oluyemi et al:: Prevalence of a marker of active helicobacter pylori infection among patients with type 2 diabetes mellitus in Lagos, Nigeria. BMC Research Notes 2012 5:284. 